\title{
ALFABETIZAÇÃO E CORRESPONDÊNCIA: ALFABETIZAÇÃO DO PONTO DE VISTA DE DOIS CANTOS DO MUNDO: UM CURSO DE FORMAÇÃO DE PROFESSORES TRABALHANDO COM ALFABETIZAÇÃ̃O ${ }^{1}$
}

\author{
ALFABETIZACIÓN Y CORRESPONDENCIA: ALFABETIZACIÓN DEL \\ PUNTO DE VISTA DE LAS ESQUINAS DEL MUNDO: UN CURSO PARA \\ MAESTROS QUE TRABAJAN CON ALFABETIZACIÓN \\ LITERACY AND CORRESPONDENCE: LITERACY FROM THE \\ STADPOINT OF TWO CORNERS OF THE WORLD: A TRAINING \\ COURSE FOR TEACHERS WORKING WITH LITERACY
}

\author{
Rosa Maria Whitaker SAMPAIO ${ }^{2}$ \\ Nerina VRETENAR ${ }^{3}$
}

RESUMO: Este artigo descreve um instrumento da Pedagogia Freinet: o ateliê. Sua leitura permite constatar a importância que tem, na Pedagogia Freinet, a busca constante da coerência entre a teoria e a prática. Temos aqui a expressão de um importante conceito desenvolvido por ele: o materialismo escolar.

PALAVRAS-CHAVE: Pedagogia Freinet. Ateliê. Educação.

RESUMEN: En este artículo se describe un instrumento de pedagogía Freinet: el estudio. Su lectura permite comprender la importancia de, en Pedagogía Freinet, la constante búsqueda de la coherencia entre la teoría y la práctica. Aquí tenemos la expresión de un concepto importante desarrollado por él: el materialismo de la escuela.

PALABRAS CLAVE: La pedagogía Freinet. Estudio. Educación.

ABSTRACT: This article describes an instrument of Freinet's Pedagogy: the atelier. Its reading allows to realize the importance of Freinet's constant pursuit of consistency between theory and practice. Here we have the expression of an important concept developed by him: the school materialism.

KEYWORDS: Freinet Pedagogy. Atelier. Education.

\footnotetext{
${ }^{1}$ Este relato foi originalmente publicado pela Associação Brasileira para Divulgação, Estudos e Pesquisas da Pedagogia Freinet (ABDEPP), na Revista Freinet no. 1, setembro de 2006, p. 22-24. Reproduzido com autorização da primeira autora.

2 Rede de Educadores e Pesquisadores da Educação Freinet (REPEF), Polo São Paulo. Email: rosamsampaio@uol.com.br.

${ }^{3}$ Movimento Freinet da Itália.
} 


\section{Introdução}

Participamos do Ateliê de Alfabetização na XXIV RIDEF, Reunião Internacional de Educadores Freinet em Varna, na Bulgária, em Julho de 2002, reunião que acontece a cada dois anos, cada vez em um país diferente, onde exista um Movimento Freinet. Esse ateliê foi desenvolvido em 15 horas, cinco dias de trabalho, três horas por dia. Formou-se um grupo com doze pessoas: brasileiros falando português ou espanhol, francês ou inglês, uma japonesa falando japonês e um pingo de espanhol, as búlgaras falando também um pouco de italiano, as italianas falando também o francês e uma suíça falando alemão e francês. Um verdadeiro quebra-cabeça multicultural e multilíngue, desenvolvendo um trabalho que vai do individual para o coletivo, voltando para o individual, sempre com a expressão livre, a cooperação, a troca de saberes, a afetividade e a responsabilidade, características essenciais da prática da Pedagogia Freinet. A seguir, o leitor acompanhará o relato das atividades, experiência e emoções vividas naqueles dias intensos.

\section{Desenvolvimento do ateliê}

Primeiro dia. Nossa primeira atividade é de escolher individualmente, entre várias fotos apresentadas, uma foto significativa sobre a ideia de alfabetização e comentar com os outros a relação encontrada. É para entrar no tema e também para se conhecerem e começarem a se comunicar. Em seguida, apresentamos um vídeo sobre a experiência italiana da Escola de Barbiana: é sobre a descoberta por um grupo de alunos da necessidade de alfabetização para elevar sua própria condição humana e também por elevar a dos outros.... Discute-se, então, essa poderosa motivação para a aprendizagem.

Segundo dia. No começo, fazemos o jogo da máquina. Para construí-la, cada um faz com seu corpo um gesto e um som que vai sendo repetido seguidamente e nos parece que está vindo de uma máquina humana bem engraçada. Isso contribui para criar a confiança e a cooperação e criar uma atmosfera de alegria.

Em seguida, trabalhamos a comunicação oral. Contamos cada um uma história na língua de nossos países, alguns em forma de canções, com o apoio de objetos e a linguagem gestual. É um momento mágico. Todos escutam. Criamos então um espaço que favorece a comunicação, que é facilitada também pelo fato das pessoas estarem 
juntas, se olhando, escutando as vozes e vendo as reações em seus rostos. Todos parecem que se entendem...

Agora, em grupos silenciosos, vamos desenhar três momentos de cada história, da forma que nós as compreendemos. A compreensão não é jamais total, mas jamais é inexistente. $\mathrm{Na}$ análise dos desenhos, discutimos sobre o fato de que isso acontece sempre que aprendemos, e sobre o fato de que, quando falamos as palavras junto com os sinais do corpo, isso ajuda a compreensão e cria a confiança. Finalizando o dia, há a reflexão sobre a comparação entre as diferentes compreensões e a intenção do autor.

Terceiro dia. Iniciamos com um esquentamento através de um jogo de confiança: sustentar os colegas antes que eles caiam. Cada um sente essa confiança no momento de se deixar cair nos braços de seus colegas, em grupos de três. Muita risada, muita alegria e sustos...

Agora era hora do trabalho sobre sons. Cada um escolhe um som ou uma sequência de sons realizada com objetos encontrados à sua volta. Jogamos individualmente e depois coletivamente e pronto: eis uma orquestra. É uma harmonia construída cooperativamente, com um sucesso inesperado que nos encanta...

No tempo seguinte, oferecemos aos participantes objetos embrulhados caprichosamente, presentes misteriosos. Todos devem escolher com suas percepções sensoriais, aquele que preferir. Cada um abre seu presente e descobre... que há um livro diferente em cada pacote.

A descoberta continua calmamente, são livros ilustrados, escritos em letras e línguas às vezes desconhecidas. Começa então uma interessante pesquisa coletiva em pequenos grupos de trabalho, para encontrar o máximo de informações sobre cada livro observado. A pesquisa é muito rica porque o livro é mais rico do que um simples texto, é um objeto concreto (com três dimensões), e há páginas com ilustrações que nos ajudam e nos estimulam. Mas a história de um livro é muito mais "fria" que uma história contada por uma pessoa com a ajuda de seu corpo. Discutimos sobre essa dificuldade "antropológica" da leitura e da escrita, que obrigam a comunicar sem a presença de uma pessoa.

Mas agora é preciso escrever. Sugestão aceita: imaginar que preparamos uma mensagem que será jogada ao mar, portadora de alguma coisa importante para a pessoa que a escreveu. Nesse momento nós trabalhamos sozinhos, para fazer a experiência da dificuldade da "escrita solitária”. É difícil também não poder pensar num destinatário concreto. Cada um coloca sua mensagem em pequenas garrafas, para continuarmos no 
dia seguinte. Fazemos então reflexões sobre a dificuldade desses aspectos da escrita para as crianças que aprendem.

Quarto dia. Eis outro jogo cooperativo: construir quatro quadrados com peças de cartão encontradas num grande envelope, isso será possível somente se houver trocas e cooperação entre todos, mesmo falando várias línguas. São momentos de alegria para todos quando se consegue chegar ao objetivo.

Num segundo momento, nós abrimos as garrafas aleatoriamente e cada um tenta decodificar a mensagem que encontrou, mesmo que elas estejam escritas em línguas que nós não conhecemos. Todos se ajudam numa troca de saberes para a descoberta de quem era a mensagem escolhida. Compreendendo as mensagens, tentamos respondê-las na mesma língua que recebemos. A troca de saberes é intensificada e essencial.

Reflexão: é bem diferente quando conhecemos o destinatário de nossas mensagens!

Quinto dia. Sobre a correspondência internacional: mostramos slides e os painéis de fotos e desenhos do trabalho da Correspondência de crianças de uma escola brasileira, "O Visconde" (da diretora Rose Moreira) em São Paulo, que fica junto à favela Real Parque. Contamos como trabalham a alfabetização das crianças a partir dessa correspondência com uma escola italiana (alunos de Nerina Vretinar). Ficam conhecendo como as crianças trabalham suas autobiografias, contam sobre suas vidas, seus sonhos, seus problemas, seus medos e seus sucessos, além de trocarem presentes, e se ajudarem mutuamente aprendendo uma nova forma de se comunicarem, pois chegam cartas numa outra língua e elas são decodificadas... Mostramos como fazem seus ateliês de cartas, as fotos, os desenhos enviados pelas crianças brasileiras, e os painéis das respostas das crianças italianas nesse feliz encontro de amizade que acontece há quatro anos. É a descoberta de um mundo desconhecido, lá do outro lado do Oceano... Discutimos entre nós a importância da correspondência escolar para que as crianças fiquem conhecendo situações de vida diferentes das suas, para criar laços, conseguindo se distanciar de seu próprio mundo para saber descrevê-lo para seus amigos. Tudo isso vai criando fortes motivações para aprender a escrever e a ler corretamente, compreendendo a importância social da comunicação escrita. Também ressaltamos as situações reais que partem de um contexto e de necessidades específicas, incentivando essa amizade de crianças que vivem em culturas diferentes... Em seguida, o grupo fez reflexões sobre os diferentes códigos de escrita e as dificuldades que a alfabetização encontra quanto à aprendizagem dos códigos. 
No sexto dia, no momento da apresentação final de todos os ateliês longos da RIDEF, montamos coletivamente uma apresentação para todos os participantes do encontro, como é feito tradicionalmente em todas as $25 \mathrm{RIDEF}$, utilizando vários elementos e situações trabalhadas pelo grupo durante o Ateliê.

\section{Referências}

SAMPAIO, Rosa Maria Whitaker. Freinet: evolução histórica e atualidades. São Paulo: Editora Scipione, 1989.

SANTOS, Maria Lúcia dos. A expressão livre no aprendizado da língua portuguesa. São Paulo: Editora Scipione, 1991.

\section{Como referenciar este artigo}

SAMPAIO, Rosa Maria Whitaker.; VRETENAR, Nerina. Alfabetização e correspondência: alfabetização do ponto de vista de dois cantos do mundo: um curso de formação de professores trabalhando com alfabetização. Revista Ibero-Americana de Estudos em Educação, Araraquara, v. 12, n. esp. 1, p.644-648, 2017. Disponível em: <http://dx.doi.org/10.21723/riaee.v12.n.esp.1.2017.9669>. E-ISSN: 1982-5587.

Submetido em: 18/03/2017

Aprovado em: 09/04/2017 